\title{
Literature review of deploying small transmitters on a spectrum sharing scheme
}

\author{
Revisión bibliográfica sobre el despliegue de transmisores pequeños en un esquema de \\ compartición de espectro \\ Juan Guillermo Torres (iD) , Roberto Bustamante (iD) 1, Carlos E. Caicedo (D) 2 \\ ${ }^{1}$ Departamento de Ingeniería Eléctrica y Electrónica, Universidad de los Andes. Carrera 1 \# 18a-12. C. P. 111711. Bogotá, \\ Colombia \\ ${ }^{2}$ School of information studies, Syracuse University. 900 South Crouse Ave. P. C. 13244. New York, United States
}

\section{CITE THIS ARTICLE AS:}

\author{
J. G. Torres, R. Bustamante \\ and C. E. Caicedo. "Literature \\ review of deploying small \\ transmitters on a spectrum \\ sharing scheme", Revista \\ Facultad de Ingeniería \\ Universidad de Antioquia, no. \\ 103, pp. 116-129, Apr-Jun \\ 2022. [Online]. Available: \\ https : \\ //www.doi.org/10.17533/ \\ udea.redin. 20210426
}

\section{ARTICLE INFO:}

Received: August 06, 2020 Accepted: April 16, 2021

Available online: April 16, 2021

\section{KEYWORDS:}

Antennas; CBRS; deployment of transmitters; sharing spectrum; $5 G$

Antenas; CBRS; compartición de espectro; despliegue de transmisores; $5 \mathrm{G}$

\begin{abstract}
Nowadays, there are a lot of misinformation and myths related to both the deployment of antennas for $5 G$ and the frequency bands used in such technology. Many of these myths arise from the lack of serious research documents released in common language to be understood by different knowledge areas. This work makes a small contribution in this regard and shows a bibliographic review of the most relevant characteristics related to the problem of deployment of transmitters la.k.a. base stations), and also takes into account a spectrum sharing scheme. As a case study, we will analyze the CBRS regulation used in the United States for the deployment of 5G, it will provide an overview of engineering problems and also, the areas of research that still need to be explored.
\end{abstract}

RESUMEN: Hoy en día existe mucha desinformación relacionada con el despliegue de antenas para $5 \mathrm{G}$ y las bandas de frecuencias que se usan en dicha tecnología. Muchos de estos mitos surgen por la falta de documentos serios de investigación divulgados con un lenguaje comprensible para diferentes audiencias. Este trabajo hace un pequeño aporte en este sentido y muestra una revisión bibliográfica de las características más relevantes relacionadas con el problema de despliegue de transmisores o estaciones base y además, se tiene en cuenta un esquema de compartición de espectro. Como caso de estudio, analizaremos la regulación CBRS implementada en los estados unidos para el despliegue de $5 G$, se brindará una visión general de los problemas de ingeniería y también, las áreas de investigación que aun faltan por explorar.

\section{Introduction}

The radio spectrum is a topic that brings together several areas of study such as: economics, technology regulation and society, among others. The reasons for its relevance are that it is an infinitely renewable natural resource and a public good. However, it is also a limited resource with an increasing demand promoted by technological innovations [1].

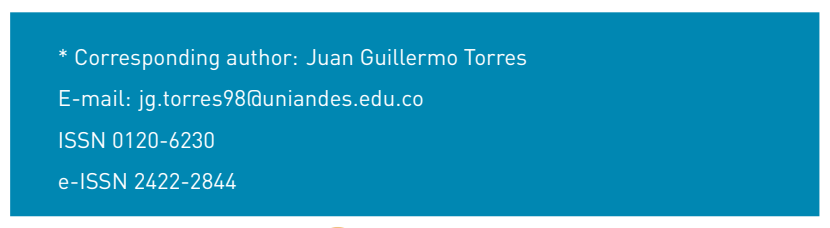

The appropriate use of spectrum leads to think of the efficient use of it, and for this purpose there are several ways to define efficiency [2] as well as hundreds of studies carried out in the last five decades [3] which allowed exploiting to the maximum such resource. However, nothing seems to satisfy the increasing demand for spectrum.

New paradigms such as dynamic access and spectrum sharing [4] have emerged as an alternative to promote its use and ease access to it. However, this would require a new regulation to achieve an agreement to all the parties within the telecommunications sector. Fortunately, the regulation known as CBRS $3.5 \mathrm{GHz}$ is a first effort 
developed in the United States of America to promote the deployment of technologies which use a spectrum sharing scheme.

At present, there are proposals from operators for commercial deployments at the band of frequencies 3600-3750 MHz under the name of OnGo [5], because the interests in the use of this band are not only of technological type, but also for the economic development of a nation $[6,7]$.

From the technological point of view, innovation resides in that regulation allows rendering any telecommunications service at these frequencies without the need to pay for the use of spectrum. Provided that, operators of previously deployed networks at these bands are protected. CBRS regulation uses a centralized scheme for managing the spectrum; which, through a SAS (Spectrum Access System) accepts or rejects operation of a transmitter and allocates channels based on its technical characteristics. In this manner such regulation allows maximizing the use of spectrum. But a better efficiency of this resource could be achieved by taking into account any other dimension such as space, time, power or frequency for example, which can be considered to maximize the spectrum efficiency in terms of capacity. The concept of spectrum efficiency has several definitions according to the objectives and resources to be compared [8]).

Similar to the emergence of mobile phone technology more than 3 decades ago [9], the deployment of transmitters has been a topic of interest in the field of telecommunications. Today it still remains a relevant topic for research due to the new challenges imposed by networks for $5 \mathrm{G}$ in terms of capacity, delay, energy efficiency, costs, among others [10]. One of the solutions in the short and medium terms is based on the deployment of small cells with different types of access technologies. Deployment of small cells are aimed to distribute the data load of current communications systems (Data offloading) [11]. This makes it necessary to perform a good management of co-channel interference, because both previously deployed transmitters and the new deployed ones interfere each other, thus, an incorrect deployment would reduce the transmission rate [12].

This work makes a small contribution in this regard and shows a bibliographic review of the most relevant characteristics related to the problem of deployment of transmitters, interference avoidance, and also spectrum sharing schemes.

This document is organized as follows. In section 2 a literature review is carried out on the problem of new transmitters deployment, taking into account previously deployed transmitters. Such review was used to identify possible research gaps in section 3 . Section 4 briefly describes CBRS $3.5 \mathrm{GHz}$ regulation and its literature review. We show in section 5 some research gaps and finally, in section 6 conclusions are shown.

\section{Deployment of transmitters}

For more than 3 decades deployment of transmitters has been an issue of interest in the field of telecommunications [9]. The first deployments of transmitters took into account the coverage and the number of transmitters to be deployed [13]. Nowadays, it continues to be a relevant issue due to the new and challenging goals imposed by networks for $5 G$ in terms of capacity, delay, energy efficiency and costs, among others [10].

One of the solutions in the short and medium terms for traffic demand [1] is based on deployment of small cells and with different types of technologies such as WiFi, LTE, and 5G. This solution would have two benefits: 1) relieve traffic in preinstalled macro cells, and 2) provide more capacity to the users. This kind of deployment could be related to Heterogeneous networks (HetNet) [14] and sometimes we also talk about ultra-dense networks (UDN) when you want to analyze as a whole the performance parameters of all types of networks deployed in a large area, e.g. a city [12].

Perhaps the most significant challenge lies in deploying new networks of small transmitters where previously there was a deployment of networks that were not designed to coexist with small cells; therefore, protection against interference between different network technologies is a crucial objective [10].

In spite of years of research, different solutions, and ways proposed through multiobjective optimization problems, neither approach has become widely accepted [15]. All these reasons motivate researchers to propose new methods of solution.

\subsection{Literature review}

This work presents the most relevant characteristics of works related to the problem of deploying small networks. Since literature is extensive, we classified the most important works according to the kind of solution, context and assumptions. We will focus on those works that solved a similar problem, and we find it convenient to study the problem of deployment of small cell for HetNet and data offloading.

Finally, the works of the last 5 years will be summarized and shown, identifying parameters, such as output, 
objective function, propagation model, positions, noise and approach or method. The information will be presented in Table 1.

Next, we will show the findings of the literature review regarding: problem statement, inputs, complexity, objective functions and solutions.

\section{Objective functions}

The problem of optimal location of transmitters generally has the following objectives: 1) to obtain the optimum number of transmitters [16], 2) to find the best locations $[17], 3)$ to select the type of base stations pico, micro and fentocells [18], 4) to define transmitter configuration parameters such as IERP [18] and the frequency allocation [19], 5) to calculate the total capacity of the network delivered to the user [20] and reduce the energy consumption [21]. Additionally, some works only focus on the location, evaluation of the number of iterations [22] and the coverage given by the proposed algorithm [18].

\section{Problem Statement}

Regarding the approach to the objective function, two methods are used. The first one consists of a linear combination of different objective functions [23, 24] (capacity, delay, energy efficiency, costs, etc.), while the second one is proposed as a set of objective functions to achieve the optimum of Pareto $[25,26]$.

\section{Inputs}

Traffic models: The demand for traffic is characterized by a distribution of users over a given area. Each user demands a certain fixed capacity [16]. Some more elaborate works include traffic models for each user for both uplink and downlink in order to allocate time and frequency resources [18].

Locations: Predefined locations are usually used in a real scenario, since the location depends on the demand of users and the suitable/available places $[23,27,28]$. Other works make the choice through random positions, and others, have a solution space in a euclidean plane $R^{2}$ [29].

Transmitter characteristics: Characteristics such as height, sensitivity, power, sectors, etc. are generally considered in the deployment of antennas [30] and transmitters. In several cases, these parameters are simplified to obtain circular coverage areas $[18,23]$, although recently, the use of spectrum consumption models has been generalized to share this information among different operators and regulatory entities [31].
Propagation models: It is perhaps the most complex element to be determined, but there are several alternatives. For example, models based on ray tracing take into account realistic phenomena such as vegetation, terrain, buildings, etc. However, it is still computationally inefficient [32] and is seldom used for the location transmitters problem $[26,33]$.

Classical models of propagation widely known as Okumura [34], Hata [35] and free space [36] are frequently used and adjusted by experimental field tests $[24,37]$. Other models consider fading phenomena as fast and slow fading $[18,28,38]$.

Despite the alternatives to be used in a cell deployment scenario, propagation models that characterize the interference are also required because traditional models could not be accurate in this context [39].

\section{Complexity}

The location transmitters problem has been classified as NP-Hard in a large number of articles [18, 20, 40, 41]. In addition, it is usually approached as a problem of multiobjective optimization, and therefore, most solutions are obtained through heuristics [42] rather than purely analytical approaches.

\section{Method of solution}

Now we will describe several methods or approaches proposed in the literature that give solution to both the problem of location and the aforementioned objectives.

\section{Strategy planning}

Some papers propose strategies to organize the problem and solve it by steps $[18,24,33,43]$ whereas other works such as $[28,44]$ focus on approximate algorithms to solve each objective function of the problem. In general terms, these works propose procedures without emphasizing any heuristic or analytical technique.

\section{Purely analytical methods}

They are used when you want to solve a single objective, whose restrictions make the problem analytically treatable. Approaches appear based on geometric concepts to determine the maximum coverage [45-47]. Sometimes these works include interference [48] but in other cases the Voronoi diagrams and the Delaunay triangulation are used [7, 18, 45, 49-55]. Stochastic geometry was used in [18] to analyze the performance of the network in terms of the probability of coverage and service, and Game theory was also used in [56]. 
Heuristic methods It is the most used method to tackle this problem in the literature. There are two heuristics widely used for deployment of transmitters in wireless networks: Tabu Search $[57,58]$ and Simulated Annealing [59-61]. Others works are based on Fuzzy logic [16, 17] and greedy algorithm [42]. Within the genetic algorithms we find variable-length genetic algorithm (VLGA) [20, 62], multiobjective genetic algorithm (MOGA) [40], Non-dominated Sorting Genetic Algorithm (NSGA-II) [63], particle swarm [64], and strength Pareto evolutionary algorithm (SPEA2) [65]. Many others propose their own algorithm as: $[66,67]$ which are not part of the above mentioned classifications.

Hybrid methods They are works that used both heuristic and analytical methods, e.g.: Hooke and Jeeves' method, Quasi-Newton, and conjugate gradient search procedures were investigated for solving this problem in [37]. In [68] it was used the Hooke and Jeeves pattern search optimization algorithm combined with vector parabolic equation (VPE). In [29], this problem was solved by Karush-Kuhn-Tucker (KKT) conditions for some subproblems, then they used an algorithm to obtain the global optimum solution.

\section{Literature gaps related deployment of transmitters}

\subsection{Number of simulations}

Most works considered few numbers of scenarios to assess their methods. This number was around 10 [24] or 100 [18, 69], but although they showed a lot of numerical results, they usually did not show CDF for all their performance metrics, which is very important to provide accurate conclusions.

\subsection{Geometric approach}

Until now, the standard Voronoi partition could not be used in a scenario where the transmitter has anisotropic characteristics (directional antennas) or where the geographical terrain is not convex [52]. [50] suggests using a generalization of the standard Voronoi partition, replacing the usual distance measure with another function associated with each site, e.g. power diagrams. But the problem with this approach will persist if it is assumed that each transmitter is placed at the centroid of the tessellations.

\subsection{Interference}

Deployment of small cells requires centralized coordination to avoid inter-cell interference and provide intelligent resource allocation in response to spatial or temporal variations [10]. Many works simplified the interference assuming coordination techniques as: CoMP, eICIC, ABS [12, 18, 70]. Other works assume circular coverages without overlaps among any transmitters [65]; however, a more complete study should take into account the uplink interference generated by the user devices.

\subsection{Locations}

Most studies that investigate this problem are based on deployments for HetNets and they generally assume prefixed locations by some arbitrary criterion. Physical location of the small cell requires more precise engineering than macro cells [10]. A slight difference between the optimal and actual location of small cell due to the physical limitations or real estate constraints can actually degrade network performance as small cell location can have large impact on interference pattern and mobility related performance. Therefore, it becomes imperative to make optimal decisions in HetNet planning for small cell locations to achieve efficient performance of the network.

\subsection{Recent works}

Finally, we want to summarize in Table 1. the most recent works (last 5 years) related to the problem addressed. The most relevant parameters have been identified, such as: type of results, objective functions, propagation models, locations (solution space), noise and solution method.

\section{Spectrum sharing scheme based on CBRS}

In the 2012 PCAST (The US President's Council of Advanced Science \& Technologyl report [6], the U.S. government proposed to explore spectrum sharing policies and technologies to share $1 \mathrm{GHz}$ spectrum with commercial systems. Then, the FCC targeted the release of the 3550-3700 MHz band for small cell deployment, termed the Citizens Broadband Radio Service (CBRS), and proposed a spectrum access framework that consists of three tiers: Incumbent Access (IA), Priority Access (PA) and General Authorized Access (GAA) as shown in Figure 1. Simultaneously, the Wireless Innovation Forum IWinn Forum) spectrum sharing committee served as a common standards body to support development of spectrum sharing standards in the band of $3.5 \mathrm{GHz}$. Therefore, this work has used as reference those standards [74] along with FCC rules defined as Part 96 (A specific section of FCC's rules that sets forth the regulations governing use of devices in CBRS) $[75,76]$ to consider both technological and regulatory CBRS aspects. 
Table 1 Parameters addressed in the literature

\begin{tabular}{|c|c|c|c|c|c|c|c|c|c|c|c|c|c|c|c|c|c|c|}
\hline \multirow[t]{2}{*}{ Paper } & \multicolumn{4}{|c|}{ Output } & \multicolumn{5}{|c|}{ Objective function } & \multicolumn{6}{|c|}{ Propagation model } & \multicolumn{2}{|c|}{ Positions } & Noise \\
\hline & 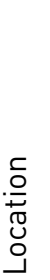 & 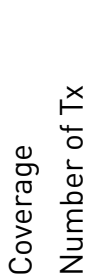 & 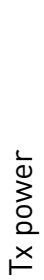 & 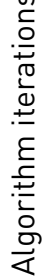 & 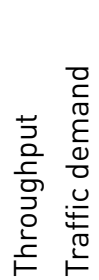 & $\begin{array}{l}n \\
0 \\
0\end{array}$ & 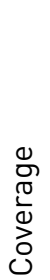 & 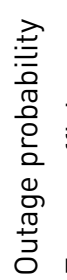 & 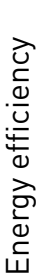 & $\begin{array}{l}0 \\
0 \\
0 \\
0 \\
0 \\
0 \\
0 \\
0 \\
\frac{1}{4}\end{array}$ & 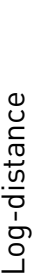 & 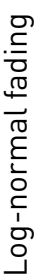 & 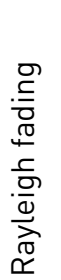 & 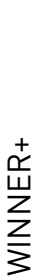 & 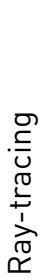 & $\begin{array}{l}0 \\
\stackrel{0}{ \pm} \\
\frac{\pi}{\pi} \\
\frac{0}{0} \\
\frac{0}{0} \\
0 \\
0\end{array}$ & 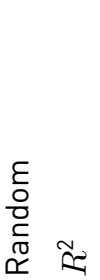 & 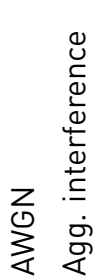 \\
\hline
\end{tabular}



\begin{tabular}{|c|c|c|c|c|c|c|c|c|}
\hline [20] & $\star$ & $\star$ & $\star$ & $\star$ & $\star$ & $\star$ & $\star$ & $\star$ \\
\hline [41] & $\star$ & & & & & $\star$ & $\star$ & \\
\hline
\end{tabular}

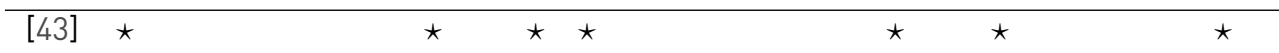

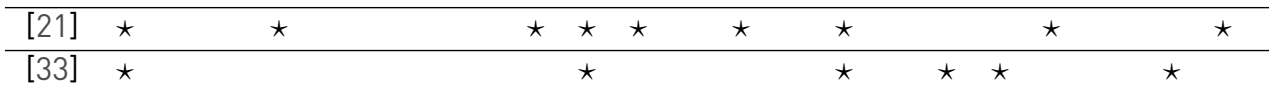

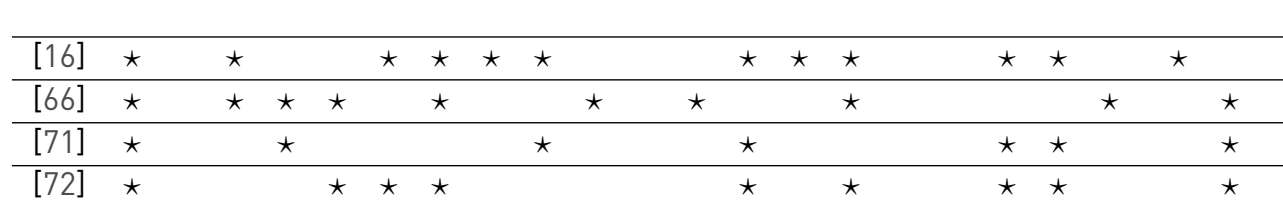

Algorithm

Fuzzy

Weighted K-means

Algorithm + Random Hill Climbing method Algorithm + VLGA

Evolutionary algorithms + VLGA Algorithms, Framework Stochastic geometry Algorithms, Framework Fuzzy Algorithm Geometric+LPOA Algorithms + Branch and bound algorithm

\begin{tabular}{|c|c|c|c|c|c|c|c|c|c|c|c|c|c|c|c|c|c|}
\hline [69] & $\star$ & & & $\star$ & & & $\star$ & & $\star$ & $\star$ & & & & $\star$ & $\star$ & $\star$ & Fuzzy \\
\hline [69] & $\star$ & & & $\star$ & & & $\star$ & & $\star$ & $\star$ & & & & $\star$ & $\star$ & $\star$ & Fuzzy \\
\hline $\begin{array}{l}{[28,} \\
44]\end{array}$ & $\star$ & * & $\star$ & * & $\star$ & $\star$ & & & * & & 夫 & & & $\star$ & $\star$ & $\star$ & Algorithm \\
\hline [73] & $\star$ & & & $\star$ & & & & $\star$ & & & & & $\star$ & $\star$ & $\star$ & 夫 & NSGA-II \\
\hline [27] & $\star$ & & & $\star$ & & $\star$ & & & $\star$ & & $\star$ & $\star$ & & & 夫 & $\star$ & K-means + NBSC \\
\hline [24] & $\star \star$ & & & $\star$ & & & & & & 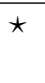 & & & & $\star$ & 夫 & * & $\begin{array}{l}\text { Algorithms, } \\
\text { Framework }\end{array}$ \\
\hline
\end{tabular}




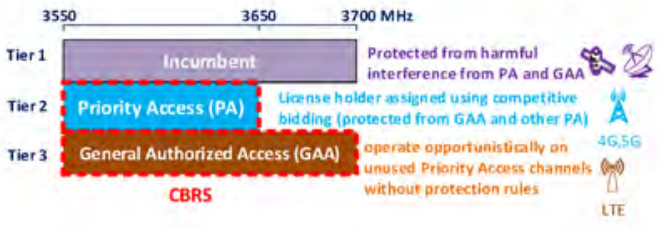

Figure 1 Three-tiered authorization framework with the FCC's spectrum access models for $3.5 \mathrm{GHz}$ CBRS band

This section will show the most relevant characteristics of this regulation and a literature review of related works. But first, we will give a brief explanation about how to use the spectrum under this new scheme.

The basic architecture for CBRS makes up of three Tiers, a CBRS manager named SAS and a sensor system named ESC. These three components are explained below.

Tiers: Incumbent Access users are federal entities authorized to operate on a primary basis. They include federal shipborne, ground-based, and airborne radar systems that operate, or are planned to operate, in and adjacent to the $3.5 \mathrm{GHz}$ band. These users will be protected from harmful interference from PA and GAA users.

The Priority Access (PA) users are holders which obtain licenses to operate up to a total of $70 \mathrm{MHz}$ (7 channels of $10 \mathrm{MHz}$ each) using competitive bidding within the 3550-3650 MHz spectrum segment. Additionally, PA users will be protected from harmful interference from GAA operations.

GAA users are permitted to use any portion of the 3550-3700 MHz band (without fees) not assigned to a higher tier user, but they should expect no interference protection and avoid causing interference to incumbents and PA users.

CBRS Manager: The $3.5 \mathrm{GHz}$ band is divided into 15 orthogonal $10 \mathrm{MHz}$ channels; the Spectrum Access System (SAS) is a system that authorizes and manages use of spectrum among tiers at a specific geographic location and time, controls the interference environment, and enforces protection criteria and exclusion zones to protect higher priority users. The SAS also takes care of registration, authentication and identification of user information and performs other functions as set forth in the FCC rules. See Figure 2 to identify each element of the SAS architecture.

ESC: Environmental Sensing Capabilities (ESC) consists of one or more commercially operated networks of sensing devices that would be used to detect signals from federal
Table 2 CBSD and End User Device emitted power limits

\begin{tabular}{llll}
\hline $\begin{array}{l}\text { CBDS } \\
\text { Type }\end{array}$ & $\begin{array}{l}\text { Maximum } \\
\text { EIRP } \\
(\mathrm{dBm} / 10 \mathrm{MHz})\end{array}$ & $\begin{array}{l}\text { Maximum } \\
\text { EIRP } \\
(\mathrm{dBm} / \mathrm{MHz})\end{array}$ & $\begin{array}{l}\text { Antenna } \\
\text { Height } \\
\text { (Meter) }\end{array}$ \\
\hline \hline $\begin{array}{l}\text { Category } \\
\text { A }\end{array}$ & $30 \mathrm{dBm}$ or $1 \mathrm{~W}$ & $20 \mathrm{dBm}$ & $<6$ meters \\
\hline $\begin{array}{l}\text { Category } \\
\text { B }\end{array}$ & $47 \mathrm{dBm}$ or $50 \mathrm{~W}$ & $37 \mathrm{dBm}$ & $>6$ meters \\
\hline $\begin{array}{l}\text { End } \\
\text { User } \\
\text { Device }\end{array}$ & $\begin{array}{l}23 \mathrm{dBm} \text { or } 200 \\
\mathrm{~mW}\end{array}$ & $\mathrm{NA}$ & $\mathrm{NA}$ \\
\hline
\end{tabular}

Reference: [74] consistent with Part 96 FCC

radar systems in the vicinity of the exclusion zones. The ESC must communicate this information to a SAS to facilitate shared spectrum access.

When an operator wants to deploy a new transmitter without the need to acquire/purchase a license for using the spectrum, it must first define the location and the technical parameters of the operation. This information is sent to the central manager known as SAS, which is responsible for assigning one or more channels. However, the SAS must ensure that other types of users are not affected by the interference from the new transmitter. Although CBRS uses a spectrum sharing scheme, previous users have clear rules for their protection against interference. Only if all the protection rules are met for the SAS or agreed among the operators, this new transmitter will be able to operate and provide a telecommunications service. Figure 2 shows the SAS notional architecture.

\subsection{Characteristics of CBRS and protection rules}

Concepts that make up the architecture of CBRS are:

Devices: Citizens Broadband Radio Service Device (CBSD) are fixed or portable base stations or access points that can only operate under the authority of a centralized SAS. An End User Device is a device authorized and controlled by an authorized CBSD (see power limits Table 2). Any CBSD must use digital modulation techniques and support transmit power control capability.

Zones: An Exclusion zone is a geographic area wherein no CBSD shall operate. A Protection zone is a geographic area in which a CBSD may operate only with permission of an approved SAS and ESC. This area is within the PA protection contour. The default $P A$ protection contour will be determined by the SAS as a $-96 \mathrm{dBm} / 10 \mathrm{MHz}$ contour 


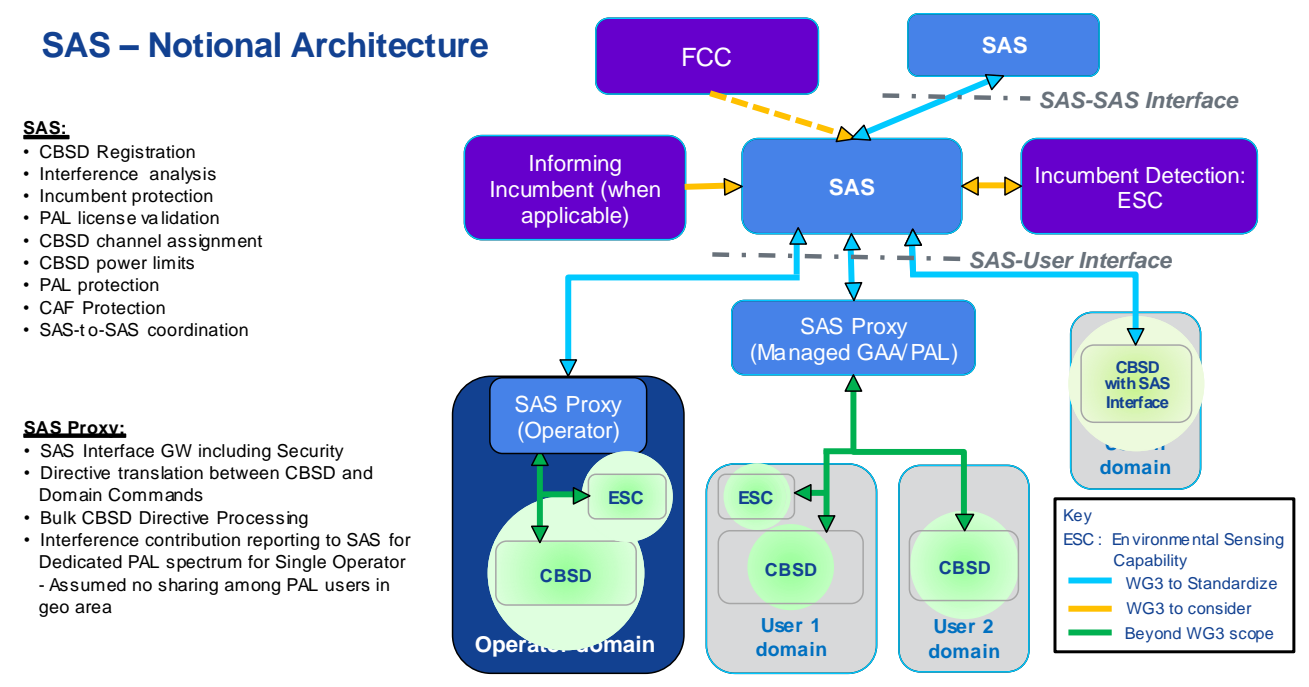

Figure 2 SAS Notional architecture

around each CBSD. The default protection contour will be calculated based on the information included in the CBSD [74].

Co-channel interference protection rules: Protection against aggregate interference for both PA and GAA users must be managed such that the aggregate received signal strength, for all locations within their PA Protection Zone of any co-channel Priority Access Licenses (PAL), shall not exceed an average (RMS) power level of $-80 \mathrm{dBm} / 10 \mathrm{MHz}$. A new CBSD must meet this criterion in its location in order to operate. Otherwise, a CBSD will not be enabled.

Adjacent interference limits: $A s$ to channel and frequency assignments made by the SAS to CBSDs, the power of any emission outside the fundamental emission shall not exceed the following levels (Figure 3 depicts these transmission restrictions):

- $-13 \mathrm{dBm} / \mathrm{MHz}$ from 0 to $10 \mathrm{MHz}$ from the assigned channel edge

- $-25 \mathrm{dBm} / \mathrm{MHz}$ beyond $10 \mathrm{MHz}$ from the assigned channel edge down to $3530 \mathrm{MHz}$ and up to $3720 \mathrm{MHz}$

- $-40 \mathrm{dBm} / \mathrm{MHz}$ below $3530 \mathrm{MHz}$ and above $3720 \mathrm{MHz}$.

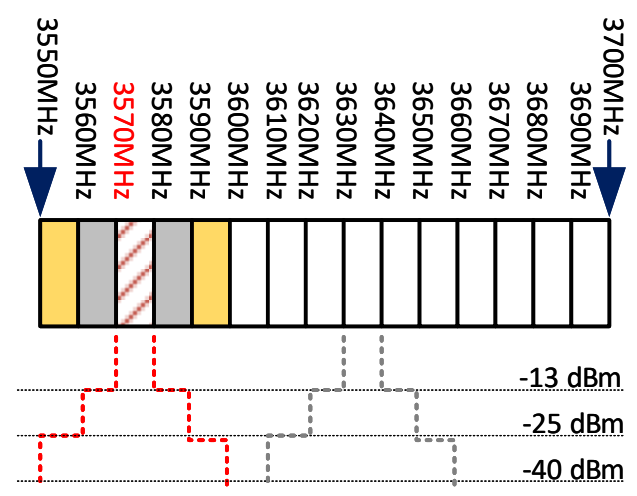

Figure 3 Emission Limits (Rule Part 96.41e)

Propagation model of path loss: The cumulative distribution function (CDF) to be used shall be the ITM[77] or eHata[78] model, according to the criteria for the specific path.

Allocation of resources: A PA user can have several transmitters, but they must be in contiguous areas, contiguous channels and have maximum 4 channels. A GAA can use any free channel anywhere, as long as it complies with the aggregate interference restriction (-80 $\mathrm{dBm} / 10 \mathrm{MHz}$. Any channel will be considered in use only within the Protection zone; outside of this area, it is a free channel.

CBSD general requirements: All CBSDs must report to SAS all operational technical specifications (power, modulation, etc.) to an accuracy of 50 meters horizontal 
and 3 meters of elevation. A CBSD must register and be authorized by a SAS prior to its initial service transmission. At any time, the SAS could either confirm suspension of the CBSD's operation or its relocation to another unoccupied frequency, if available.

\subsection{Related literature to CBRS}

This research has considered works related to spectrum sharing within the CBRS context after 2015 because regulatory rules were not completely stable before that year. In summary, this section shows open research areas related to CBRS in different fields such as: security, sensing, markets, spectrum allocation, and interference management. Additionally, other subjects have been included in this review such as: CBRS regulatory standards, experimental and technical deployments, and CBRS perspectives to cover a wide scope.

In short, Table 3 contains a list of analyzed references and mentions the main topic each one addressed as well as a brief description of their contributions.

\section{Sensing}

A new spectrum sensing technique for CBSD is shown in [99], which can be developed to provide more efficient spectrum opportunity identification than geolocation database methods. This work was assessed through simulations along with experimental and numerical results. The work [98] studied different detection techniques, starting from classical methods as energy detection and matched filtering, classical machine learning techniques such as support vector machine (SVM) and $k$-nearest neighbor (KNN), up to state of-the-art methods such as convolutional neural networks (CNNs) and long short-term memory (LSTM) recurrent neural networks. On the other hand, [100] proposed a methodology for determining the ESC's required sensitivity as a function of CBSD deployment. The authors also minimized the number of sensors to mitigate security concerns of the federal incumbent. They approached this problem as a well-known set cover problem, which is NP-complete. Finally, they gave solutions with a greedy algorithm.

\section{Security}

Malicious queries can infer locations of incumbents by making multiple queries to the database [92]. To address this issue, this paper proposed a perturbation-based optimal obfuscation strategy that can be implemented by the SAS to preserve the location privacy of incumbents. [93] explored whether primary users can retain a critical level of privacy in a spectrum access system setting where they must reveal some information to enable dynamic access to the spectrum by other users.

\section{Interference management}

A new optimization framework [94] is proposed in order to select the maximum number of secondary users (SU) and compute power allocations to satisfy instantaneous rate or QoS requirements of SUs. Optimization framework also aimed to restrict the interference to primary users (PUs) below a predefined threshold. Nevertheless, traditional assumptions and simplifications such as: circular coverage areas, log-distance propagation model, and Gamma PDF for interference were used. [95] is another NTIA work that investigated the co-channel and adjacent channel coexistence of a ship-borne naval radar with a wide-area cellular communication system. [96] used stochastic geometry (homogeneous Poisson point process) for characterizing the performance of this spectrum sharing system and provided approximate expressions for the coverage probability of a typical CBRS user.

\section{Spectrum allocation}

According to [90], the role of the SAS is to allocate channels to two types of users (PAL and GAA) while providing interference protection to incumbent users. The authors proposed a channel allocation algorithm to be used by the SAS. The proposed algorithm allocates channels to the CBRS users in two steps: 1) allocate channels to the PAL users and 2) allocate channels to the GAA users. In this work, the interference was handled by moving away the transmitter; however, coverage and interference protection areas were assumed circular. The work [91] developed an algorithm to identify coexistence on the same channel. The authors used a generic graph approach to formulate and solve this optimization problem. [89] is a later work based on [91]. Apart from the former comments, the authors approximated solutions by heuristic-based algorithms that search for the maximum weighted independent set. The authors showed that the utility function is submodular, and the problem is an instance of matroid-constrained submodular maximization. As a result, a local-search based polynomial-time algorithm was proposed. The dynamic spectrum allocation scheme was studied in [19], exploring its impact on spectrum availability and stability of GAA users. This paper developed a mathematics and probabilistic model to analyze the performance of spectrum sharing, with regards to both PAL users and GAA users.

\section{Experimental and technical deployments}

Technical works as [86] described the first SAS-CBRS field trial using a live LTE network in the $3.5 \mathrm{GHz}$ band. This work evaluated the performance of a CBRS field trial in a spectrum sharing scenario. In [87], 
Table 3 Summary of contribution from related works

\begin{tabular}{|c|c|c|c|}
\hline Topic & Year & Ref & Contribution \\
\hline \multirow[t]{5}{*}{ Overview-Perspectives } & 2019 & [1] & $\begin{array}{l}\text { shows important figures of market, industry, data traffic, and behavior } \\
\text { of users of mobile services. }\end{array}$ \\
\hline & 2018 & [79] & introduces technical challenges and enabling technologies for $5 \mathrm{G}$ \\
\hline & 2016 & [80] & $\begin{array}{l}\text { shows spectrum regulation initiatives and open problems in dynamic } \\
\text { spectrum sharing }\end{array}$ \\
\hline & 2016 & [70] & overviews different schemes used for LTE deployments in $3.5 \mathrm{GHz}$ band \\
\hline & 2016 & [81] & $\begin{array}{l}\text { analyzes the sources of value creation regarding the CBRS spectrum } \\
\text { sharing }\end{array}$ \\
\hline \multirow[t]{2}{*}{ Markets } & 2018 & [82] & $\begin{array}{l}\text { presents an economic analysis of the spectrum market in a CBRS } \\
\text { scenario }\end{array}$ \\
\hline & 2017 & [5] & shows new business models for CBRS \\
\hline \multirow[t]{4}{*}{$\begin{array}{l}\text { Regulation } \\
\text { Standards }\end{array}$} & 2018 & [31] & $\begin{array}{l}\text { proposes the standard IEEE P1900.5.2 to share the information among } \\
\text { the CBRS elements }\end{array}$ \\
\hline & 2016 & [83] & $\begin{array}{l}\text { studies the effectiveness of census tracts as units of area to license } \\
\text { channels }\end{array}$ \\
\hline & 2015 & [78] & $\begin{array}{l}\text { provides technical and deployment parameters of each CBSD and the } \\
\text { methodology used to compute exclusion zones }\end{array}$ \\
\hline & 2015 & [84] & presents in a brief the framework defined by NTIA \& FCC for CBRS \\
\hline \multirow[t]{4}{*}{$\begin{array}{l}\text { Experimental } \\
\text { deployments }\end{array}$} & 2018 & [85] & $\begin{array}{l}\text { proposes LTE (RP-ABS) mechanism to mitigate interference to pulse } \\
\text { radar }\end{array}$ \\
\hline & 2018 & [86] & $\begin{array}{l}\text { evaluates the time for each SAS state in the evacuation and frequency } \\
\text { change process }\end{array}$ \\
\hline & 2018 & [87] & $\begin{array}{l}\text { deploys an outdoor scenario based on LBT mechanism for GAA } \\
\text { coexistence }\end{array}$ \\
\hline & 2018 & [88] & $\begin{array}{l}\text { evaluates the total network capacity within an existing LTE network and } \\
\text { its effect on new technologies as CBRS }\end{array}$ \\
\hline \multirow[t]{4}{*}{ Spectrum allocation } & 2018 & [19] & proposes a channel allocation algorithm and models it mathematically \\
\hline & 2018 & [89] & $\begin{array}{l}\text { allocates channels using graphs, and finds solutions by classical } \\
\text { heuristic methods }\end{array}$ \\
\hline & 2017 & [90] & $\begin{array}{l}\text { allocates channels through an optimization problem, and solve it using } \\
\text { its algorithm }\end{array}$ \\
\hline & 2017 & [91] & proposes a generic graph representation to model the interference \\
\hline \multirow[t]{2}{*}{ Security } & 2018 & [92] & $\begin{array}{l}\text { addresses the problem for military users when their transmitters are } \\
\text { discovered }\end{array}$ \\
\hline & 2018 & [93] & develops strategies to keep incumbent users hidden \\
\hline \multirow[t]{4}{*}{$\begin{array}{l}\text { Interference } \\
\text { management }\end{array}$} & 2018 & [94] & $\begin{array}{l}\text { addresses the power control and channel allocation problem to predict } \\
\text { the throughput }\end{array}$ \\
\hline & 2017 & [95] & $\begin{array}{l}\text { proposes power control algorithms to reduce the protection distances } \\
\text { base on co-channel and adjacent interference. }\end{array}$ \\
\hline & 2017 & [96] & $\begin{array}{l}\text { provides expressions for the GAA coverage probability and spectral } \\
\text { efficiency }\end{array}$ \\
\hline & 2016 & [97] & $\begin{array}{l}\text { uses machine learning techniques to optimize the transmission duty } \\
\text { cycle }\end{array}$ \\
\hline \multirow[t]{3}{*}{ Sensing } & 2019 & [98] & $\begin{array}{l}\text { demonstrates that machine learning algorithms outperform classical } \\
\text { signal detection methods. }\end{array}$ \\
\hline & 2018 & [99] & $\begin{array}{l}\text { proposes an autonomous compressive sensing-based sensing } \\
\text { algorithm }\end{array}$ \\
\hline & 2017 & $\begin{array}{l}{[100,} \\
101]\end{array}$ & $\begin{array}{l}\text { presents methods for both deploying ESC sensors and setting up } \\
\text { detection thresholds }\end{array}$ \\
\hline
\end{tabular}


the authors examined the design and implications of contention-based channel access for the lowest CBRS tier that comprises opportunistic GAA users. In particular, they assessed the suitability of Listen-BeforeTalk (LBT) for GAA channel access using Nokia (MulteFire) devices. The work [85] proposed both power-domain and time-domain LTE interference coordination method based on LTE reduced-power almost blank subframe (RP-ABS) for pulse radar spectrum sharing. First, the authors built a link-level simulation platform based on software. After that, they deployed both systems on a Keysight test bed achieving similar results with their simulations. [97] used a reinforcement learning multiarm bandit (MAB) based adaptive duty cycle section for the coexistence between LTE-U and WiFi. As a result, the authors found a significant throughput improvement for both systems

\section{CBRS regulation}

A brief of fundamental regulatory concepts related to the CBRS service appeared initially in [84], showing different interest groups' standpoint on the FCC framework proposed. At the same time, a NTIA framework [78] explained the assumptions, methods, analyses, and system characteristics used to generate exclusion zones for small-cell to protect federal radar operations from aggregate interference. Additionally, this work explained how to implement the eHATA propagation model.

The Federal Communications Commission (FCC) has adopted the census tract demographic areas as the licensing area units for sharing the $3.5 \mathrm{GHz}$ band. Hence, [83] explored which implications this choice has on efficient spectrum usage. And finally, [31] proposed the spectrum consumption model being standardized under the IEEE 1900.5.2 working group to unify the information among spectrum sharing schemes, as CBRS. This standard is a means to inform and establish how each CBSD or SAS use spectrum resources in a particular scenario and at a specific location.

\section{Markets}

There are few works addressed from the economic point of view. The work [82] showed the variation of profit of a mobile operator with licensed/unlicensed access as a function of the bandwidth. The most important conclusion was that to unlicensed access, different information ways are needed to promote competition, and this characteristic can lead to better economic welfare. CBRS offers cost-effective LTE solutions for both indoor and outdoor applications and opens up new use cases. The work [5] explained those use cases for real deployments, e.g.: Capacity augmentation with up 15 GAA channels allow mobile operators to apply carrier aggregation to boost peak speeds, and Mobile virtual operators like cable operators and new entrants are also an option for traffic offloading, which are expected to gain access into the mobile industry and improve the QoS.

\section{CBRS perspectives}

[81] is a survey that identified and studied the potential benefits of the CBRS concept by using the dynamic spectrum access approach. This work focused on defining key CBRS functional domains and identifying their background, elements, and outcomes. The analysis highlights the role of the regulator in creating a sharing framework with incentives for all the key stakeholders. [80] provided a current overview of major technological and regulatory reforms toward more flexible, dynamic and market-based ways to manage and share spectrum resources. It focused on current efforts to implement database-driven approaches for managing the co-existence of users with heterogeneous access and interference protection rights. [79] focused on advanced antenna and filtering solutions as the main enabler for operation at mmWave bands. The authors also emphasized that there is a potential spectrum under-used in the frequency bands below $6 \mathrm{GHz}$ as $3300-4200 \mathrm{MHz}$, 4400-5000 MHz, and $700 \mathrm{MHz}[102,103]$. [70] showed that adapting LTE cellular technologies by means of formal LBT and ABS proposals (which became part of LTE standards) is feasible for improving the system QoS and coexistence management. Recently, [1] showed some interesting figures, for example: the number of global LTE connections grew by more than 1 billion within one year, from 2.51 billion in June 2017 to 3.59 billion in June 2018 (with a growth rate of $43 \%$ ). At the end of the second quarter 2017 Latin America and the Caribbean had 241 million LTE subscriptions (which means a $52 \%$ annual rate of growth since June 2017). By 2022, it is forecast to have almost 400 million connections worldwide [1]. According to this work, the average time spent on social media apps increased globally between 2014 and 2018 by almost $60 \%$, from $30 \mathrm{~min}$ a day in 2014 to $47 \mathrm{~min}$ in 2018.

\section{CBRS literature gaps}

After the literature review, we can indicate some relevant characteristics of all CBRS works. First, most of them did not consider the aggregate interference, and others, only took into account the white noise. This could give rise to inaccurate results when calculating the transmitter capacity and coverage.

Second, apart from [93], the rest of works used a free space propagation model to calculate coverage and interference. But, even a log-distance model could generate inaccuracies for interference estimations. The work [78] analyzed Okomura's work for distances up to $100 \mathrm{~km}$ and, as a result, the authors found that the exponential attenuation 
coefficient proportionally decreases as a function of the distance, when the distance is greater than $20 \mathrm{~km}$, then an eHata model is proposed to suit better in a CBRS scenario. Third, protection and coverage areas were simplified as a circular shape which is not real. And fourth, most of these works assumed that the interference coordination is handled by GAA devices without a clear explanation about which technology or protocol could be used.

Those works show that we are still in an initial phase of the study on the effects and scope of the CBRS regulation. The studies need to be improved by involving multidisciplinary areas. And although most works are technical, they should address the phenomena of wave propagation models, interference, resource allocation algorithms, etc. in more detail. Good technical studies that comprise social and economic issues will strengthen the regulation of the spectrum under a sharing scheme.

\section{Conclusions}

This work reviewed the deployment of new small cells in order to provide more capacity to users of a previously deployed network, and here we summarize the most important results. The problem of locating a single transmitter has been stated as an optimization problem considering the constraints of CBRS regulation. New geometric methods must be rethought to include both geometric constraints and CBRS protection zones.

The problem of locating several transmitters has been solved through many algorithms to locate several transmitters together. This makes that the solution provided any algorithm not be constrained within a polynomial-time expression.

It is well known that interference affects any metric in a telecommunications system, we need to understand how interference affects capacity and coverage for each transmitter deployed. These metrics together define the maximum number of transmitters that can be deployed based on a CBRS regulation.

eHata propagation model is based on the traditional Hata propagation model and has been adapted to work at a frequency of $3.5 \mathrm{GHz}$. Capacity and coverage metrics depend on these models; therefore, more accurate propagation and scenario models for small cells, especially in indoor areas that include slow and fast fading would help estimate those metrics in a more realistic way than statistical models.

\section{Acknowledgement}

This work has been funded by the Colombian Ministry of Science, Technology and Innovation under grant 614-2013 for doctoral-level education.

\section{References}

[1] M. Patzold. $5 \mathrm{~g}$ is coming around the corner [mobile radio]. IEEE Vehicular Technology Magazine, 14(1):4-10, mar 2019.

[2] M. Hoyhtya, A. Mammela, M. Eskola, M. Matinmikko, J. Kalliovaara, J. Ojaniemi, J. Suutala, R. Ekman, R. Bacchus, and D. Roberson. Spectrum occupancy measurements: A survey and use of interference maps. IEEE Communications Surveys and Tutorials, pages 1-1, 2016.

[3] F. H. Sanders, K. E. Davis, and K. D. Gremban. Ntia technical report $\operatorname{tr}-18-530$ a 53-year history of spectrum efficiency studies and recommended future directions. Technical report, National Telecommunications and Information Administration, 2018.

[4] R. H. Tehrani, S. Vahid, D. Triantafyllopoulou, H. Lee, and K. Moessner. Licensed spectrum sharing schemes for mobile operators: A survey and outlook. IEEE Communications Surveys and Tutorials, pages 1-1, 2016.

[5] K. Mun. Ongo white paper: Ongo: New shared spectrum enables flexible indoor and outdoor mobile solutions and new business models. Mobile Experts, 2018.

[6] The US President's Council of Advanced Science and Technology. Realizing the full potential of govt-held spectrum to spur economic growth. Technical report, President's Council of Advisors on Science and Technology, 2012, Washington D. C., 2012.

[7] J. G. Torres. Methodology and analysis of small cells deployment aimed at offering offloading service under the spectrum sharing scheme. Ph.d. dissertation, Universidad de los Andes, Colombia, 2020.

[8] FCC Spectrum Policy Task Force. Report of the spectrum efficiency working group. Technical report, FCC, 2002.

[9] J. S. Rose, W. M. Snelgrove, and Z. G. Vranesic. Parallel standard cell placement algorithms with quality equivalent to simulated annealing. IEEE Transactions on Computer-Aided Design of Integrated Circuits and Systems, 7(3):387-396, mar 1988.

[10] A. Taufique, M. Jaber, A. Imran, Z. Dawy, and E. Yacoub. Planning wireless cellular networks of future: Outlook, challenges and opportunities. IEEE Access, 5:4821-4845, 2017.

[11] F. Rebecchi, M. Dias de Amorim, V. Conan, A. Passarella, R. Bruno, and M. Conti. Data offloading techniques in cellular networks: A survey. IEEE Communications Surveys and Tutorials, 17(2):580-603, 2015.

[12] J. Andrews, S. Singh, Q. Ye, X. Lin, and H. Dhillon. An overview of load balancing in hetnets: old myths and open problems. IEEE Wireless Communications, 21(2):18-25, apr 2014.

[13] J. D. Wells. Cellular system design using the expansion cell layout method. IEEE Transactions on Vehicular Technology, 33(2):58-66, may 1984.

[14] J. G. Andrews. Seven ways that hetnets are a cellular paradigm shift. IEEE Communications Magazine, 51(3):136-144, mar 2013.

[15] E. Zitzler, L. Thiele, M. Laumanns, C. M. Fonseca, and V.G. da Fonseca. Performance assessment of multiobjective optimizers: an analysis and review. IEEE Transactions on Evolutionary Computation, 7(2):117-132, apr 2003.

[16] M. Arthi and P. Arulmozhivarman. A flexible and cost-effective heterogeneous network deployment scheme for beyond $4 \mathrm{~g}$. Arabian Journal for Science and Engineering, 41(12):5093-5109, dec 2016.

[17] J. Y Chang and Y. S. Lin. An efficient base station and relay station placement scheme for multi-hop relay networks. Wireless Personal Communications, 82(3):1907-1929, jun 2015.

[18] Y. C Wang and C. A. Chuang. Efficient enb deployment strategy for heterogeneous cells in $4 \mathrm{~g}$ lte systems. Computer Networks, 79:297-312, mar 2015.

[19] C. S. Xin, P. Paul, M. Song, and Q. Gu. On dynamic spectrum allocation in geo-location spectrum sharing systems. IEEE Transactions on Mobile Computing, pages 1-1, 2018.

[20] O. Abdelkhalek, S. Krichen, and A. Guitouni. A genetic algorithm based decision support system for the multi-objective node placement problem in next wireless generation network. Applied Soft Computing, 33:278-291, aug 2015. 
[21] J. Peng, P. Hong, and K. Xue. Energy-aware cellular deployment strategy under coverage performance constraints. IEEE Transactions on Wireless Communications, 14(1):69-80, jan 2015.

[22] P. Kapadia, O. Damani, and A. Kumar. Interference constrained coverage algorithms in the protocol and sinr models. Wireless Networks, 21(4):1391-1409, may 2015.

[23] X. Huang and S. Wang. Aggregation points planning in smart grid communication system. IEEE Communications Letters, 19(8):1315-1318, aug 2015.

[24] D. Schweitzer and H. Medal. Wireless lan transmitter location under the threat of jamming attacks. Computers and Operations Research, 106:14-27, jun 2019.

[25] O. Abdelkhalek, N. Dahmani, S. Krichen, and A. Guitouni. Vl-pls: A multi-objective variable length pareto local search to solve the node placement problem for next generation network. Procedia Computer Science, 73:250-257, jan 2015.

[26] G. Koutitas, A. Karousos, and L. Tassiulas. Deployment strategies and energy efficiency of cellular networks. IEEE Transactions on Wireless Communications, 11(7):2552-2563, jul 2012.

[27] Y. C Wang and S. Lee. Small-cell planning in lte hetnet to improve energy efficiency. International Journal of Communication Systems, 31(5):e3492, mar 2018.

[28] W. Zhao, S. Wang, C. Wang, and X. Wu. Cell planning for heterogeneous networks: An approximation algorithm. In IEEE INFOCOM 2014 - IEEE Conference on Computer Communications, pages 1087-1095. IEEE, apr 2014.

[29] S. Yin, Y. Zhao, and L. Li. Resource allocation and basestation placement in cellular networks with wireless powered uavs. IEEE Transactions on Vehicular Technology, 68(1):1050-1055, jan 2019.

[30] J. Y Wang, J. B Wang, and M. Chen. System capacity analysis and antenna placement optimization for downlink transmission in distributed antenna systems. Wireless Personal Communications, 71(1):531-554, jul 2013.

[31] C. E. Caicedo Bastidas, J. A. Stine, A. Rennier, M. Sherman, A. Lackpour, M. M. Kokar, and R. Schrage. leee 1900.5.2: Standard method for modeling spectrum consumption: Introduction and use cases. IEEE Communications Standards Magazine, 2(4):49-55, dec 2018.

[32] E. M. Vitucci, V. Degli-Esposti, F. Fuschini, J. S. Lu, M. Barbiroli, J. N. Wu, M. Zoli, J. J. Zhu, H. L. Bertoni, E. M. Vitucci, V. Degli-Esposti, F. Fuschini, J. S. Lu, M. Barbiroli, J. N. Wu, M. Zoli, J. J. Zhu, and H. L. Bertoni. Ray tracing rf field prediction: An unforgiving validation. International Journal of Antennas and Propagation, pages 1-11, 2015.

[33] D. Li, J. Weng, X. Chu, and J. Zhang. A network deployment strategy for home area networks in smart grid. In 2015 IEEE 26th Annual International Symposium on Personal, Indoor, and Mobile Radio Communications (PIMRC), pages 2160-2165. IEEE, aug 2015.

[34] Y. Okumura, E. Ohmori, T. Kawano, and K. Fukuda. Fieldstrength and its variability in vhf and uhf land mobile radio service, 1968.

[35] M. Hata. Empirical formula for propagation loss in land mobile radio services. IEEE Transactions on Vehicular Technology, 29(3):317-325, aug 1980.

[36] T. S. Rappaport. Wireless communications: principles and practice. Prentice Hall PTR, 1996.

[37] H. D. Sherali, C. M. Pendyala, and T. S. Rappaport. Optimal location of transmitters for micro-cellular radio communication system design. IEEE Journal on Selected Areas in Communications, 14(4):662-673, may 1996

[38] J. G. Torres, R. Bustamante, and C. E. Caicedo. Characterizing the mobile coverage probability in different geometries. IEEE Latin America Transactions, 17(8):1342-1348, aug 2019.

[39] J. G. Andrews, X. Zhang, G. D. Durgin, and A. K. Gupta. Are we approaching the fundamental limits of wireless network densification? IEEE Communications Magazine, 54(10):184-190, oct 2016.

[40] 0. Abdelkhalek, H. Masri, and S. Krichen. An adaptive variable neighborhood search for solving the multi-objective node placement problem. Electronic Notes in Discrete Mathematics, 47:189-196, feb 2015
[41] S. Lee, S. Lee, K. Kim, and Y. H. Kim. Base station placement algorithm for large-scale lte heterogeneous networks. PLOS ONE, 10(10):e0139190, oct 2015.

[42] C. W Tsai, H. H. Cho, T. K. Shih, J. S Pan, and J. J. P. C. Rodrigues. Metaheuristics for the deployment of $5 \mathrm{~g}$. IEEE Wireless Communications, 22(6):40-46, dec 2015.

[43] J. M. Ruiz Aviles, M. Toril, and S. Luna Ramirez. A femtocell location strategy for improving adaptive traffic sharing in heterogeneous Ite networks. EURASIP Journal on Wireless Communications and Networking, 2015(1):38, dec 2015.

[44] W. Zhao, S. Wang, C. Wang, and X. Wu. Approximation algorithms for cell planning in heterogeneous networks. IEEE Transactions on Vehicular Technology, 66(2):1561-1572, feb 2017.

[45] G. K. Das, S. Das, S. C. Nandy, and B. P. Sinha. Efficient algorithm for placing a given number of base stations to cover a convex region. Journal of Parallel and Distributed Computing, 66(11):1353-1358, nov 2006.

[46] N. Lev-Tov and D. Peleg. Polynomial time approximation schemes for base station coverage with minimum total radii. Computer Networks, 47(4):489-501, mar 2005.

[47] M. Franceschetti, M. Cook, and J. Bruck. A geometric theorem for network design. IEEE Transactions on Computers, 53(4):483-489, apr 2004.

[48] H. S. Jo, Y. J. Sang, P. Xia, and J. G. Andrews. Heterogeneous cellular networks with flexible cell association: A comprehensive downlink sinr analysis. IEEE Transactions on Wireless Communications, 11(10):3484-3495, oct 2012.

[49] Tianyang Bai and R. W. Heath. Location-specific coverage in heterogeneous networks. IEEE Signal Processing Letters, 20(9):873-876, sep 2013.

[50] K. R. Guruprasad. Effectiveness-based voronoi partition: a new tool for solving a class of location optimization problems. Optimization Letters, 7(8):1733-1743, dec 2013.

[51] A. Abdel Khalek, L. Al-Kanj, Z. Dawy, and G. Turkiyyah. Optimization models and algorithms for joint uplink/downlink umts radio network planning with sir-based power control. IEEE Transactions on Vehicular Technology, 60(4):1612-1625, may 2011.

[52] M. Argany, M. A. Mostafavi, F. Karimipour, and C. Gagne. A GIS Based Wireless Sensor Network Coverage Estimation and Optimization: A Voronoi Approach. Springer, Berlin, Heidelberg, 2011.

[53] J. S. Li and H. C. Kao. Distributed k-coverage self-location estimation scheme based on voronoi diagram. IET Communications, 4(2):167, 2010.

[54] A. Tzes and Y. Stergiopoulos. Convex voronoi-inspired space partitioning for heterogeneous networks: a coverage-oriented approach. IET Control Theory and Applications, 4(12):2802-2812, dec 2010.

[55] J. G. Torres, R. Bustamante, and C. E. Caicedo. Optimal and fast deployment of small cell based on voronoi tessellation. Technical report, Universidad de los Andes, Bogota, 2019.

[56] E. Altman, A. Kumar, C. Singh, and R. Sundaresan. Spatial sinr games combining base station placement and mobile association. In IEEE INFOCOM 2009 - The 28th Conference on Computer Communications, pages 1629-1637. IEEE, apr 2009

[57] C. Y. Lee and H. G. Kang. Cell planning with capacity expansion in mobile communications: a tabu search approach. IEEE Transactions on Vehicular Technology, 49(5):1678-1691, 2000.

[58] E. Amaldi, A. Capone, and F. Malucelli. Planning umts base station location: optimization models with power control and algorithms. IEEE Transactions on Wireless Communications, 2(5):939-952, sep 2003.

[59] S. Hurley. Planning effective cellular mobile radio networks. IEEE Transactions on Vehicular Technology, 51(2):243-253, mar 2002.

[60] M. Unbehaun and M. Kamenetsky. On the deployment of picocellular wireless infrastructure. IEEE Wireless Communications, 10(6):70-80, dec 2003.

[61] M. Randall, G. McMahon, and S. Sugden. A simulated annealing approach to communication network design. Journal of Combinatorial Optimization, 6(1):55-65, 2002. 
[62] T. Chuan-Kang, L. Chung-Nan, C. Hui-Chun, and W. Jain-Shing. Wireless heterogeneous transmitter placement using multiobjective variable-length genetic algorithm. IEEE Transactions on Systems, Man, and Cybernetics, Part B (Cybernetics), 39(4):945-958, aug 2009

[63] A. L. Rezaabad, H. Beyranvand, J. A. Salehi, and M. Maier. Ultra-dense $5 \mathrm{~g}$ small cell deployment for fiber and wireless backhaul-aware infrastructures. IEEE Transactions on Vehicular Technology, 67(12):12231-12243, dec 2018.

[64] H. Ghazzai, E. Yaacoub, M. S. Alouini, Z. Dawy, and A. Abu-Dayya. Optimized lte cell planning with varying spatial and temporal user densities. IEEE Transactions on Vehicular Technology, 65(3):1575-1589, mar 2016.

[65] N. Weicker, G. Szabo, K. Weicker, and P. Widmayer. Evolutionary multiobjective optimization for base station transmitter placement with frequency assignment. IEEE Transactions on Evolutionary Computation, 7(2): 189-203, apr 2003.

[66] U. Challita, Z. Dawy, G. Turkiyyah, and J. Naoum-Sawaya. A chance constrained approach for lte cellular network planning under uncertainty. Computer Communications, 73:34-45, jan 2016.

[67] S. Lee, S. Lee, K. Kim, D. Griffith, and N. Golmie. Optimal deployment of pico base stations in lte-advanced heterogeneous networks. Computer Networks, 72:127-139, oct 2014.

[68] X. Zhang, A. Ludwig, N. Sood, and C. D. Sarris. Physics-based optimization of access point placement for train communication systems. IEEE Transactions on Intelligent Transportation Systems, 19(9):3028-3038, sep 2018.

[69] M. Arthi and P. Arulmozhivarman. Power-aware fuzzy based joint base station and relay station deployment scheme for green radio communication. Sustainable Computing: Informatics and Systems, 13:1-14, mar 2017.

[70] Y. Ye, D. Wu, Z. Shu, and Y. Qian. Overview of lte spectrum sharing technologies. IEEE Access, 4:8105-8115, 2016.

[71] A. Kundu, S. K. Sanyal, and I. S. Misra. Joint location and power optimisation of femto base stations to improve indoor coverage: a geometric approach. Transactions on Emerging Telecommunications Technologies, 27(11):1496-1512, nov 2016.

[72] J. Zhang, N. E, and X. Chu. Small-cell deployment over existing heterogeneous networks. Electronics Letters, 52(3):241-243, feb 2016.

[73] R. E. Badra and G. E. Figueras. Optimal lte femtocell indoor deployment under external intra-system interference. In 2018 IEEE Symposium on Electromagnetic Compatibility, Signal Integrity and Power Integrity (EMC, SI and PI), pages 598-603. IEEE, jul 2018.

[74] Wireless Innovation Forum. Requirements for commercial operation in the u.s. $3550-3700 \mathrm{mhz}$ citizens broadband radio service band. Technical report, WIF, 2018.

[75] FCC. $47 \mathrm{cfr}$ part 96 - citizens broadband radio service. Technical report, FCC, 2019.

[76] Federal Communications Commission. Fcc 16-55: In the matter of amendment of the commission's rules with regard to commercial operations in the 3550- $3650 \mathrm{mhz}$ band, 2016.

[77] S. P. Tonkin. A tutorial on the hata and itm propagation models: Confidence, reliability, and clutter with application to interference analysis. Technical report, University of Washington Seattle, 2017.

[78] R. Sole E. Drocella, J. Richards, F. Najmy, A. Lundy, and P. McKenna. $3.5 \mathrm{ghz}$ exclusion zone analyses and methodology. Report 15-517, page 103, 2015.

[79] J. Lee, E. Tejedor, K. Ranta-aho, H. Wang, K. T. Lee, E. Semaan, E. Mohyeldin, J. Song, C. Bergljung, and S. Jung. Spectrum for $5 \mathrm{~g}$ : Global status, challenges, and enabling technologies. IEEE Communications Magazine, 56(3):12-18, mar 2018.

[80] S. Bhattarai, J. M. Park, B. Gao, K. Bian, and W. Lehr. An overview of dynamic spectrum sharing: Ongoing initiatives, challenges, and a roadmap for future research. IEEE Transactions on Cognitive Communications and Networking, 2(2):110-128, jun 2016.

[81] S. Yrjola, M. Matinmikko, M. Mustonen, and P. Ahokangas. Analysis of dynamic capabilities for spectrum sharing in the citizens broadband radio service. Analog Integrated Circuits and Signal Processing, 91(2):187-201, may 2017.
[82] A. Ghosh, R. A. Berry, and V. Aggarwal. Spectrum measurement markets for tiered spectrum access. IEEE Transactions on Cognitive Communications and Networking, 4(4):929-941, dec 2018.

[83] E. Avdic, I. Macaluso, N. Marchetti, and L. Doyle. Census tract license areas: Disincentive for sharing the $3.5 \mathrm{ghz}$ band? In 2016 IEEE Global Communications Conference (GLOBECOM), pages 1-7. IEEE, dec 2016.

[84] M. M. Sohul, M. Yao, T. Yang, and J. H. Reed. Spectrum access system for the citizen broadband radio service. IEEE Communications Magazine, 53(7):18-25, jul 2015.

[85] L. Yin, S. Li, H. Zhu, Y. Ma, Y. Teng, and H. Liu. Reduced-power almost black subframe based pulse radar spectrum sharing for Ite system. IEEE Transactions on Electromagnetic Compatibility, 60(5):1223-1230, oct 2018.

[86] M. Palola, M. Hoyhtya, P. Aho, M. Mustonen, T. Kippola, M. Heikkila, S. Yrjola, V. Hartikainen, L. Tudose, A. Kivinen, R. Ekman, J. Hallio, J. Paavola, M. Makelainen, and T. Hanninen. Field trial of the $3.5 \mathrm{ghz}$ citizens broadband radio service governed by a spectrum access system (sas). In 2017 IEEE International Symposium on Dynamic Spectrum Access Networks (DySPAN), pages 1-9. IEEE, mar 2017.

[87] R. Karaki and A. Mukherjee. Coexistence of contention-based general authorized access networks in $3.5 \mathrm{ghz}$ cbrs band. In 2018 IEEE 87th Vehicular Technology Conference (VTC Spring), pages 1-6. IEEE, jun 2018.

[88] F. W. Vook, A. Ghosh, E. Diarte, and M. Murphy. $5 \mathrm{~g}$ new radio: Overview and performance. In 2018 52nd Asilomar Conference on Signals, Systems, and Computers, pages 1247-1251. IEEE, oct 2018.

[89] X. Y. Roy, Milind M. Buddhikot, and Sumit. Sas-assisted coexistence-aware dynamic channel assignment in cbrs band. IEEE Transactions on Wireless Communications, pages 1-1, 2018.

[90] K. B. Shashika Manosha, S. Joshi, T. Hanninen, M. Jokinen, P. Pirinen, H. Posti, K. Horneman, S. Yrjola, and M. Latva-aho. A channel allocation algorithm for citizens broadband radio service/spectrum access system. In 2017 European Conference on Networks and Communications (EuCNC), pages 1-6. IEEE, jun 2017.

[91] X. Ying, M. M. Buddhikot, and S. Roy. Coexistence-aware dynamic channel allocation for $3.5 \mathrm{ghz}$ shared spectrum systems. In 2017 IEEE International Symposium on Dynamic Spectrum Access Networks (DySPAN), pages 1-2. IEEE, mar 2017.

[92] S. Bhattarai, P. Reddy Vaka, and J. M. Park. Thwarting location inference attacks in database-driven spectrum sharing. IEEE Transactions on Cognitive Communications and Networking. 4(2):314-327, jun 2018.

[93] M. A. Clark and K. Psounis. Trading utility for privacy in shared spectrum access systems. IEEE/ACM Transactions on Networking, 26(1):259-273, feb 2018.

[94] S. Chaudhari and D. Cabric. Qos aware power allocation and user selection in massive mimo underlay cognitive radio networks. IEEE Transactions on Cognitive Communications and Networking, 4(2): 220-231, jun 2018.

[95] N. N. Krishnan, R. Kumbhkar, N. B. Mandayam, I. Seskar, and $\mathrm{S}$. Kompella. Coexistence of radar and communication systems in cbrs bands through downlink power control. In MILCOM 2017 - 2017 IEEE Military Communications Conference, pages 713-718. IEEE, oct 2017.

[96] P. Parida, H. S. Dhillon, and P. Nuggehalli. Stochastic geometry-based modeling and analysis of citizens broadband radio service system. IEEE Access, 5:7326-7349, 2017.

[97] I. Parvez, M. G. S. Sriyananda, I. Guvenc, M. Bennis, and A. Sarwat. Cbrs spectrum sharing between lte- $u$ and wifi: A multiarmed bandit approach. Mobile Information Systems, 2016:1-12, 2016.

[98] W. M. Lees, P. Wunderlich, A.and Jeavons, P. D. Hale, and M. R. Souryal. Deep learning classification of $3.5 \mathrm{ghz}$ band spectrograms with applications to spectrum sensing. IEEE Transactions on Cognitive Communications and Networking, pages 1-1, 2019.

[99] X. Zhang, Y. Ma, Y. Gao, and W. Zhang. Autonomous compressive-sensing-augmented spectrum sensing. IEEE Transactions on Vehicular Technology, 67(8):6970-6980, aug 2018.

[100] T. T. Nguyen, M. R. Souryal, A. Sahoo, and T. A. Hall. 3.5 
ghz environmental sensing capability detection thresholds and deployment. IEEE Transactions on Cognitive Communications and Networking, 3(3):437-449, sep 2017.

[101] T. T. Nguyen, A. Sahoo, M. R. Souryal, and T. A. Hall. 3.5 ghz environmental sensing capability sensitivity requirements and deployment. In 2017 IEEE International Symposium on Dynamic Spectrum Access Networks (DySPAN), pages 1-10. IEEE, mar 2017.
[102] J. G. Torres and R. Bustamante. Analysis of the effects of cqi feedback for lte networks on ns-3. IEEE Latin America Transactions, 13(11):3538-3543, nov 2015.

[103] J. G. Torres and R. Bustamante. Effects of cqi feedback for lte networks. In 2014 IEEE 9th IberoAmerican Congress on Sensors, IBERSENSOR 2014 - Conference Proceedings. IEEE, dec 2014. 